\title{
SABERES E COMPETÊNCIAS DO PROFESSOR UNIVERSITÁRIO: CONTRIBUIÇÕES PARA O ESTUDO DA PRÁTICA PEDAGÓGICA DO PROFESSOR DE CIÊNCIAS CONTÁBEIS DO BRASIL
}

\section{ACQUIREMENTS AND COMPETENCES OF THE UNIVERSITY PROFESSOR: CONTRIBUTIONS FOR THE ACCOUNTING PROFESSOR PEDAGOGICAL PRACTICE STUDY}

\author{
VILMA GENI SLOMSKI \\ Pós-doutoranda em Controladoria e Contabilidade pela Universidade de São Paulo \\ Professora Pesquisadora da Fundação Escola de Comércio Álvares Penteado \\ E-mail: vilma@institutofibonacci.com.br \\ Esta pesquisa conta com apoio financeiro da FAPESP - Fundação de Amparo à Pesquisa do Estado de São Paulo
}

\section{Resumo}

A docência como profissão baseia-se na idéia de que o ensino demanda saberes próprios, é assim, um ofício feito de saberes. Este artigo apresenta e discute as novas tendências investigativas sobre a formação de professores que valorizam os saberes docentes e defendem a docência como profissão. A revisão bibliográfica aqui discutida servirá de base para uma pesquisa sobre a competência pedagógica do professor de Ciências Contábeis no Brasil. 0 trabalho apresentado caracteriza-se como um ensaio teórico que segundo Severino (2000) consiste na exposição lógicoreflexiva com ênfase na argumentação e interpretação pessoal. Os saberes que servem de base para o ensino, tais como são revelados pelos estudos, são adquiridos por meio de processos que abrangem a história de vida pessoal dos docentes, a formação profissional para o magistério, o conhecimento científico da disciplina que ensina, os currículos e materiais instrucionais com que trata o professor, e, finalmente, a prática de ensino. Nesse sentido, os saberes profissionais são plurais, abrangem diferentes categorias e são adquiridos através de processos de aprendizagem e socialização que atravessam tanto a história de vida quanto a carreira docente.

Palavras-Chave: docência no ensino superior; professor universitário; formação de professores; didática; prática de ensino.

\begin{abstract}
Teaching as a profession is based on the idea that education demands its own acquirements, being known a "labor made of acquirements". This paper presents and discusses the new researching tendencies about teachers' formation, which appraise professors' acquirements and defend teaching as a profession. The bibliographic review discussed here will be the basis for an inquiry about pedagogical competence of the Accounting Professor in Brazil. The work presented here is characterized as a theoretical essay which, according to Severino (2000), consists on logic and reflexive exposure emphasizing argumentation and personal interpretation. The acquirements that serve as ground for teaching, as it is revealed by the literature, are acquired through processes that embrace professors' personal life history, their professional formation for teaching, their scientific knowledge about the discipline they teach, the curricula and material which the professor works with and, finally, the teaching practice. In this sense, professional acquirements are plural, take different categories and are acquired through learning processes and socialization which go through both professor's history of live and teaching carrer.
\end{abstract}

Key words: university teaching, university professor, teacher formation, didactics, teaching practice. 


\title{
INTRODUÇÃO
}

\begin{abstract}
O sentido essencial da responsabilidade social da educação de nível superior consiste em produzir e socializar conhecimentos que tenham não só mérito científico, mas também valor social e formativo. Portanto, que sejam importantes para o desenvolvimento econômico, mas prioritariamente, que tenham sentido de cidadania pública. (...) Que "a universidade não dê razão ao mercado se e quando ele se impõe como razão da sociedade, que a universidade não seja um motor de globalização da economia de mercado, mas sim da globalização da cidadania e da dignidade humana".
\end{abstract}

(SOBRINHO, 2005, p. 172-173).

O texto em epígrafe indica que a função da universidade neste milênio é parametrizar-se pela qualidade do trabalho acadêmico que realiza e pela competência dos profissionais que forma. A sociedade atual vive um momento de crise e questionamentos, em que cada vez mais se reconhece a importância do acesso à informação e à escolarização em todos os níveis. Nesse contexto, a instituição universitária torna-se foco de atenção, pelo questionamento da qualidade do conhecimento nela produzido e dos processos educativos pelos quais é responsável, visando à disseminação do conhecimento científico e à formação de profissionais de diferentes áreas.

À medida que aumentam as demandas externas por excelência acadêmica e pertinência social da instituição, alguns reflexos se fazem sentir internamente, basicamente pelos processos de auto-avaliação que estão sendo desencadeados, na busca de um diagnóstico sobre a situação real vivida pela academia e de alternativas para resolver as questões que se colocam sobre o seu papel (KOURGANOFF, 1990).

Quando se questiona o desempenho do profissional formado pela Universidade, é a qualidade do ensino ministrado que, concretamente, é objeto de avaliação. Esse dado remete à reflexão sobre o papel do docente, quanto à prática do ensino universitário e à construção de um projeto pedagógico que concretize os objetivos da Universidade como instituição produtora do conhecimento científico e formadora de profissionais competentes para a difusão do saber e do desenvolvimento social. Somente a Universidade pode realizar, ao mesmo tempo, a formação profissional e a integração da ciência à cultura, exigindo que seus professores atuem como educadores.

Isso indica que a formação pedagógica do professor universitário é tema primordial quando se discute a melhoria da qualidade de ensino na graduação. E a quem cabe tal tarefa? Os estudos sobre a formação de professores investigam a genealogia da profissão docente, procurando identificar e compreender quais conhecimentos e saberes ela demanda em contraposição à perspectiva histórica da profissão ligada a um fazer vocacionado, em que os conhecimentos profissionais reduzem-se ou ao conteúdo de ensino ou à idéia de missão.

A idéia de que a docência é um ofício feito de saberes está relacionada às perspectivas da literatura educacional, que entende que a docência requer a construção de um repertório próprio de saberes.

A docência, no sentido etimológico tem suas raízes no latim - docere, e significa ensinar, instruir, mostrar, indicar, fazer entender, que. Conforme Araújo (2004), o registro do termo na Língua Portuguesa é de 1916; o que implica dizer que a sua utilização, ou melhor, apropriação, é algo novo no espaço dos discursos sobre a educação. No sentido formal, docência é o trabalho dos professores, os quais desempenham um conjunto de funções que ultrapassam as tarefas de ministrar aulas. As funções formativas convencionais como, ter um bom conhecimento sobre a disciplina e sobre como explicá-la, foram tornando-se mais complexas com o tempo e com o surgimento de novas condições de trabalho. 
Zabalza (2004) atribui três funções aos professores universitários: o ensino (docência); a pesquisa; e a administração em diversos setores da instituição. Acrescento ainda a função de orientação acadêmica: monografias, dissertações e teses.

Novas funções agregam-se a essas, tornando mais complexo o exercício profissional. A Lei 9394/96, em seu art. 13, estabelece as seguintes incumbências para os professores: “a) participar da elaboração do projeto pedagógico; b) elaborar e cumprir o plano de trabalho; c) zelar pela aprendizagem dos alunos; d) estabelecer estratégias de recuperação para alunos de menor rendimento; d) ministrar os dias letivos e horas-aula estabelecidos; e) participar integralmente dos períodos dedicados ao planejamento, à avaliação e ao desenvolvimento profissional".

Não há dúvida de que estamos diante de um processo de ampliação do campo da docência universitária. A docência requer formação profissional para seu exercício: conhecimentos específicos ou, no mínimo, habilidades vinculadas à atividade docente para melhorar sua qualidade.

O novo modelo de formação profissional, hoje defendido no Brasil, percebe o professor como um profissional que ocupa um lugar de destaque; e a prática pedagógica, como uma instância de "produção" de saberes e competências (GAUTHIER, 1998; PERRENOUD, 1996, 1999; SHÖN, 2000; TARDIF, 2000, 2002). Segundo Gauthier (1998) nessa visão, o papel do professor é o de dominar certas competências e saberes para agir individual e/ ou coletivamente no exercício de sua profissão, a fim de ser reconhecido como aquele que conhece as especificidades de seu trabalho.

$\mathrm{Na}$ discussão sobre os saberes da ação docente, Tardif (2000) destaca a natureza dos saberes subjacentes ao ato de ensinar como um conjunto de conhecimentos, competências e habilidades que alicerçam a prática docente. Ele reconhece algumas idéias pré-concebidas, como: ao professor basta saber o conteúdo; ou ter talento; ou ter bom senso; ou seguir a intuição; ou ter experiência/ cultura. Na maioria das vezes, dois ou mais desses preconceitos acham-se articulados. Por outro lado, aponta como saberes necessários ao ensino: a formação pedagógica (ciências da educação); saber disciplinar (conhecimento específico); e o saber da experiência (prática de ensino).

Nesse sentido, a docência é uma atividade que demanda saberes próprios e inscreve-se como profissão. Profissão é uma palavra de construção social. É uma realidade dinâmica e contingente, calcada em ações coletivas. É produzida pelas ações dos atores sociais, no caso, os docentes universitários.

Analisando a situação dos professores que atuam hoje nas salas de aula da universidade, verifica-se facilmente que, com exceção dos docentes provenientes das licenciaturas, a grande maioria não contou com a formação sistemática necessária à construção de uma identidade profissional para a docência. Embora estejam dando aulas, esses professores, nem sempre dominam as condições necessárias para atuar como tais.

Essa problemática precisa ser considerada tanto no que se refere à identidade, que diz sobre o que é ser professor, quanto no que se refere à profissão, que diz sobre as condições do seu exercício. O que identifica um professor? E um professor universitário? Essas questões têm sido consideradas em vários países, tanto no âmbito da pesquisa sobre os processos de formação, como nas formulações das políticas de ensino superior, em respeito ao ensino e à pesquisa, exigências que caracterizam o exercício da profissão de modo geral.

Essas questões apontam para a necessidade de se valorizar tanto o ensino como a pesquisa na formação do professor universitário, uma vez que as repercussões do processo evolutivo de pensar o conhecimento e reorganizar a ciência estão trazendo profundas modificações para o mundo contemporâneo. É importante observar como essas duas esferas andam juntas, já que ambas decorrem de uma visão epistemológica. 
A docência universitária exige a indissociabilidade entre ensino, pesquisa e extensão e, faz parte dessa característica integradora, a produção do conhecimento, bem como sua socialização.

Tal indissociabilidade aponta para a atividade reflexiva e problematizadora do futuro profissional e articula componentes curriculares e projetos de pesquisa e de intervenção. O conhecimento científico produzido pela universidade não é para mera divulgação, mas para a melhoria de sua capacidade de decisão. Nesse sentido, Forgrad (2001) considera que o ensino como extensão "[...] aponta para a formação contextualizada às agudas questões da sociedade contemporânea" (p. 31), e o ensino como pesquisa "[...] aponta para o verdadeiro domínio dos instrumentos nos quais cada profissão se expressa em seu próprio processo evolutivo" (p.31).

As novas tendências investigativas sobre a formação e o desenvolvimento profissional do professor e os novos achados na área da didática do ensino superior têm despertado o seguinte questionamento: Quais são os processos que estruturam e dão sentido às práticas pedagógicas dos professores, especificamente dos universitários? Nessa direção caminha o presente artigo, que tem por objetivo apresentar e discutir tais tendências investigativas que valorizam os saberes que os docentes produzem em suas práticas pedagógicas, defendendo a docência como profissão. Esse referencial teórico será utilizado para uma pesquisa sobre as competências pedagógicas do professor de Ciências Contábeis que atua no Brasil.

Quanto aos aspectos metodológicos, este trabalho caracteriza-se como um ensaio teórico, que segundo Severino (2000) consiste na exposição lógico-reflexiva com ênfase na argumentação e interpretação pessoal. 0 material consultado foi submetido ao método de leitura científica, que segundo Cervo e Bervian (2002) obedece a passos sistematizados cronologicamente tais como: visão sincrética, visão analítica, leitura crítico-reflexiva, visão sintética e leitura interpretativa. Tomaram-se como ponto de partida estudos e pesquisas sobre a formação de professores que entendem a docência como profissão e buscou-se identificar e explicitar os conhecimentos e saberes que essa profissão demanda, especialmente, na educação de nível superior.

Espera-se que as reflexões aqui contidas possam contribuir para a ampliação das discussões sobre a profissão docente, especialmente, do ensino superior de Ciências Contábeis no Brasil, conhecimento esse, que pode ser elemento decisivo para ampliar a compreensão sobre o cotidiano da universidade e os processos e dificuldades na formação dos professores.

\section{A DOCÊNCIA COMO PROFISSÃO}

A década de 80 marca a intensificação do movimento de profissionalização do ensino, e, com isso, um apelo para a constituição de um repertório de conhecimentos docentes. $O$ estudo da profissão docente tem sido objeto de interesse de educadores e pesquisadores como: García, 1992, 1998; Shulman, 1987; Tardif, 1991, 1999; Perrenoud, 1996, 1999; Schön, 1987, 2000; Nóvoa, 1992, 1995; Pimenta, 1999, 2002; Sacristán, 1995 entre outros.

Essas pesquisas trouxeram importante contribuição à compreensão da docência como profissão. Entre as distintas possibilidades de abordagem dessa temática, salientamse, de forma destacada nos últimos anos, as reflexões que procuram compreender a genealogia dessa profissão, isto é, os conhecimentos e saberes que ela demanda. Esse esforço, certamente, tem raízes na preocupação de ultrapassar a concepção histórica da 
docência ligada a um fazer vocacionado, cujos conhecimentos reduzem-se ao conteúdo de ensino ou à idéia de missão, tornando nebulosa a perspectiva profissional, compreendida no contexto da organização social do trabalho.

Em vista da necessidade de entendimento e localização da docência no âmbito profissional, os estudos da sociologia das profissões sustentaram as análises do magistério como profissão, usando as características funcionais de seu exercício, tendo como referência desejável os profissionais liberais Enguita (1991), Hipólyto (1991), Apple (1991), Cunha (2001). Tais estudos trouxeram importantes contribuições, pois com eles aprendeuse a ver o professor no contexto da relação educação e trabalho na sociedade capitalista, compreendendo que muitas das nossas constatações, em termos de exercício e formação, estavam permeadas por relações de poder definidas na macro estrutura social. Ultrapassava-se a perspectiva de que a dimensão pedagógica daria conta dos desafios da docência e esse salto favoreceu a análise sociológica da escola e das condições de trabalho do professor.

Entretanto, essa importante compreensão não foi suficiente para responder questões ligadas aos aspectos da subjetividade do professor, tão necessária para a análise das práticas cotidianas no interior das escolas. Ainda que tenha sido fundamental entender e alterar a lógica que aprisiona e determina as relações de poder no mundo do trabalho, ficou evidente que a compreensão da profissão docente exige a inclusão de outros processos analíticos. Entre eles, estabeleceu-se, com destaque, a construção dos saberes e dos valores responsáveis pela produção cotidiana do trabalho do professor. É certo que a docência sofre determinações do sistema e da sociedade, provocando processos de reprodução social. Mas é reconhecido, também, que os professores são sujeitos históricos, capazes de transformações, especialmente, quando se sentem protagonistas de seu fazer profissional.

Esse entendimento desencadeou esforços no sentido de compreender o trabalho do professor e favorecer sua formação na direção da autonomia de seus processos de produção de práticas e conhecimentos. No Brasil, cabe destacar a influência pioneira de Stenhouse que, já na década de 70 , defendia a idéia do professor pesquisador, depois reforçada por Donald Schön nos anos 80 , que inseriu a idéia do professor reflexivo. $\mathrm{Na}$ década de 90, os estudos de Kenneth Zeichner e, posteriormente, Philippe Perrenoud tiveram amplo impacto no mundo acadêmico interessado nas questões da docência. Fortalecendo a influência espanhola, Angel Perez Gomes e José Gimeno Sacristan (1995) auxiliaram a reflexão sistemática, fazendo pontes entre os espaços do conhecimento e a profissão de professor, enquanto as idéias de António Nóvoa (1992) trouxeram importante contribuição dos estudos portugueses à compreensão da docência como profissão.

Mas o Brasil não foi só tributário das reflexões estrangeiras. Nessa direção, destacam-se as contribuições de Paulo Freire e seu impacto nas idéias pedagógicas contemporâneas, com repercussões no mundo inteiro. Mesmo sem tomar a docência como ponto particular de análise, Freire delineou uma revolucionária forma de ver a educação e seus agentes.

A compreensão de que os pressupostos da racionalidade técnica, que definiram os conhecimentos necessários para docência na modernidade, eram absolutamente insuficientes para dar conta da complexidade da docência, estimulou outros caminhos. Nessa direção, a influência dos estudos sociológicos e etnográficos re-configuraram as tradicionais formas de analisar e pesquisar a educação e, consequentemente, a profissão docente. Entre os primeiros estudos, no país, destacam-se os de Kramer (1984), Lüdke (1988), Veiga (1989), Pimentel (1993) e André (1994), que inauguraram um grande contingente de dissertações e teses, procurando entender o professor e a prática pedagógica que se desenvolviam socialmente. 
Como decorrência dessa compreensão, identificou-se uma inversão na lógica investigativa. Não mais se partia das matrizes e explicações teóricas para confirmá-las na prática. Ao contrário, tomavam-se o real e o cotidiano como objetos abertos de estudo e procurava-se, a partir da apreensão da prática, encontrar explicações teóricas. Por exemplo, não se definia, a priori, quais os conhecimentos e saberes necessários ao professor com uma base rígida alicerçada no dever ser e no dever fazer. Ao contrário, ia-se ao campo entender como os professores, de fato, atuavam e a que saberes eles recorriam para enfrentar os desafios de sua profissão. Instalou-se a busca de uma genealogia, não como um fim em si mesma, mas como ponto principal de referência para avançar o conhecimento e construir teorias que pudessem ajudar a explicação dos fenômenos. Essa perspectiva distanciou-se das grandes generalizações, porque procurou valorizar tanto as regularidades como as especificidades das construções pedagógicas cotidianas. A cotidianidade assumiu uma importância significativa na compreensão do mundo e os estudos de Heller (1985), no campo da filosofia, foram uma preciosa ajuda para a construção da pesquisa e da reflexão sistematizada. Esse arcabouço histórico e conceitual do entendimento da docência e da mudança paradigmática que vem afetando a concepção de conhecimento, incluindo novas racionalidades, tem influenciado, significativamente, a formação de professores no Brasil.

\section{PESQUISAS SOBRE A APRENDIZAGEM DA DOCÊNCIA}

Vários autores têm identificado o domínio de conhecimento que um professor deve possuir para exercer sua profissão docente (García, 1992, 1998; Shulman, 1987; Tardif, 1991, 1999; Perrenoud, 1996; Schön, 1987, 2000; Nóvoa, 1992, 1995; Pimenta, 1999, 2002; Sacristán, 1995; Sacristán, 1995 entre outros). Tais estudos procuram desvendar a seguinte questão: o que um professor de Matemática, de História, de Química, de Direito, de Ciências Contábeis etc., deve saber para ingressar na profissão docente?

A base de conhecimento para o ensino consiste de um corpo de compreensões, conhecimentos, habilidades e disposições que são necessários para que o professor possa propiciar processos de ensinar e de aprender, em diferentes áreas de conhecimento, níveis, contextos e modalidades de ensino (MIZUKAMI, 1996). Para essa autora, a base envolve conhecimentos de diferentes naturezas, todos necessários e indispensáveis para a atuação profissional. É mais limitada em cursos de formação inicial, e se torna mais aprofundada, diversificada e flexível a partir da experiência profissional refletida e objetivada. Não é fixa e imutável. Implica construção contínua, já que muito ainda está para ser descoberto, inventado, criado.

Muitos pesquisadores vêm estudando a base de conhecimento profissional para o ensino a partir de uma variedade de perspectivas teórico-metodológicas. Há estudos que focalizam fontes e fundamentos das compreensões dos professores, procurando estabelecer relações entre os conhecimentos por eles construídos ao longo de sua vida profissional e aqueles adquiridos em cursos de formação inicial e/ ou programas de formação continuada. Há estudos que focalizam processos cognitivos envolvidos tanto na proposição quanto no desenvolvimento de atividades que o professor planeja. Há outros que consideram o conhecimento do professor, com foco nos conteúdos de seus pensamentos - o conhecimento que o professor tem do aluno, do currículo, de teorias pedagógicas, de fins e metas educacionais etc. Tais estudos, embora não conclusivos, têm contribuído para compreensões sobre o que o professor pensa e sobre como aprende a ser professor. Têm gerado, igualmente, uma série de classificações/ tipologias que possuem elementos em comum, mas também sutilezas idiossincráticas tais como Tardif et al (1991), Shulman (1987), Schön (1983, 1987), Perrenoud (2000)2 . 
Em síntese, esses trabalhos podem ser agrupados segundo duas vertentes: a) conteúdos do conhecimento (foco nos componentes que o constituem); e b) conhecimento na ação (ênfase no modo como é criado e aplicado o conhecimento na docência).

Considerando os estudos estrangeiros que têm servido de referência para as pesquisas brasileiras, colocando em evidência diferentes tipologias e apresentando a complexidade e o caráter polissêmico que envolve a noção de saber docente e, nesse sentido, dos saberes que são mobilizados pelo professor em sua prática pedagógica, Tardif et al. (1991) destacam que:

"quanto mais um saber é desenvolvido, formalizado, sistematizado, como acontece com as ciências e os saberes contemporâneos, mais se revela longo e complexo o processo de aprendizagem que exige, por sua vez, uma formalização e uma sistematização adequada" (p. 219).

Nessa direção, destacam-se os estudos desenvolvidos por Schön (1983, 1987), que considera a prática como uma grande influência no conhecimento profissional do professor. Ao defender que o saber profissional se revela, sobretudo, na ação, sublinha a importância de se estudar este tipo de conhecimento, designado "conhecimento-na-ação". Fazendo, o professor aprende e utiliza o pensamento como um meio para a ação concreta. Contudo, ao desenvolver a idéia do professor como um profissional reflexivo, Schön (1987) considera que é o processo de reflexão sobre a prática (tanto durante como após a ação) que promove e desenvolve o seu conhecimento profissional. Assim, para esse autor existem, ainda, dois conceitos que se completam e influenciam o conhecimento profissional: a) "reflexão-na-ação", ligada à produção de grande parte do conhecimento; e b) reflexão sobre a ação e sobre a "reflexão-na-ação", em que o professor analisa, numa fase posterior, as características e os processos da sua própria ação.

Outro autor que estuda o conhecimento profissional do professor é Shulman (1986), que identifica grandes áreas, tais como: a) conhecimento do conteúdo disciplinar; b) conhecimento pedagógico do conteúdo (pedagogical content knowledge); e c) conhecimento pedagógico geral.

Dessas três categorias, o autor considera que o conhecimento pedagógico do conteúdo estabelece a síntese entre a pedagogia e o conteúdo. Ele o classifica como o "traço mais distintivo do conhecimento profissional do professor". Esse investigador valoriza, para além do conhecimento do conteúdo que o professor ensina, a forma como esse conhecimento é traduzido num tipo de ensino que promova uma efetiva compreensão por parte dos alunos. Para Shulman (1987), o domínio do conhecimento é influenciado tanto pelo "conteúdo específico da disciplina", quanto pelo "conteúdo pedagógico geral" e emerge e se desenvolve quando os professores transformam seu conhecimento de conteúdo específico, de acordo com os "objetivos" do ensino. Para o autor, esse conhecimento, específico da docência, pode ser considerado como um novo tipo de conhecimento, porque incorpora os aspectos do conteúdo mais relevantes a serem estudados. Dentro da categoria de conhecimento pedagógico de conteúdo, incluem-se os tópicos mais importantes a serem ensinados, e nisso, as "representações mais úteis de tais idéias, as analogias mais poderosas, ilustrações, exemplos, explanações e demonstrações. (...) também inclui uma compreensão do que torna a aprendizagem de tópicos específicos fácil ou difícil: as concepções e pré-concepções que estudantes de diferentes idades e repertórios trazem para as situações de aprendizagem" (SHULMAN, 1986, p.9).

Shulman (1987), no seu modelo do conhecimento, entende que o domínio de "conteúdo específico da área" é essencial, pois os professores devem conhecer mais do que simples fatos, termos e conceitos de uma disciplina. "A organização e conexão das idéias, formas de pensar e de argumentar a construção do conhecimento dentro da disciplina é um fator importante" (SHULMAN, 1987, p. 676). 
Entretanto, o autor salienta que, embora o conhecimento do conteúdo específico seja necessário ao ensino, o domínio dele, por si só, não garante que ele seja ensinado e aprendido com sucesso. Para Shulman, os professores devem encontrar formas de comunicar conhecimentos para os outros (...) "eles devem ter dois tipos de conhecimento da matéria: conhecimento da área tanto em seus aspectos genéricos quanto em suas especificidades e conhecimento de como ajudar seus estudantes a entender a matéria" (1987, p. 109).

Já Elbaz (1983) afirma que o conhecimento do professor tem um caráter fundamentalmente prático. É um conhecimento que se forma para exercer a prática pedagógica, a qual the vai dando corpo. O próprio conhecimento da disciplina, adquirido de forma teórica, é desenvolvido e refinado durante as experiências de ensino. Essa autora diferencia diversos domínios de conhecimento do professor, entre os quais se destacam: a) conhecimento do conteúdo, que engloba o conhecimento da disciplina e das áreas que estudam o desenvolvimento e a aprendizagem dos alunos, bem como as teorias sociais; e b) conhecimento experiencial, que é orientado pelo conhecimento do conteúdo. É a conjugação dessas duas vertentes do conhecimento com os seus valores, crenças e teorias pessoais - a que a autora chama de conhecimento prático do professor - que determina a forma como esse profissional atua nas situações de sala de aula. Elbaz considera duas possíveis origens do conhecimento prático do professor, a teoria e a experiência. Sem negar o papel da primeira, ele valoriza a prática no desenvolvimento do saber.

Essas referências estrangeiras têm orientado a busca de novos caminhos de pesquisa sobre os saberes e a formação docente na realidade brasileira. Tais estudos apresentam características próprias, conforme a análise de alguns trabalhos que se apresentará a seguir.

A fim de repensar a formação inicial e contínua a partir da análise das práticas pedagógicas, Pimenta (1999) desenvolveu uma pesquisa a partir de sua prática com alunos de licenciatura e destacou a importância da mobilização dos saberes da experiência para a construção da identidade profissional do professor. Nesse sentido, identificam-se três tipos de saber da docência: a) "da experiência", que seria aquele aprendido pelo professor quando aluno, com os professores significativos etc., assim como o que é produzido na prática num processo de reflexão e troca com os colegas; b) "do conhecimento", que abrange a revisão da função da escola na transmissão dos conhecimentos e as suas especialidades num contexto contemporâneo; e c) "dos saberes pedagógicos", que abrangem a questão do conhecimento juntamente com o saber da experiência e dos conteúdos específicos, e que serão construídos a partir das necessidades pedagógicas reais. A autora enfatiza ainda a importância de superar a fragmentação entre os diferentes saberes, considerando a prática social como objetivo central, possibilitando, assim, uma re-significação dos saberes na formação dos professores.

Guarnieri (1997) desenvolve um estudo acerca da atuação de professores iniciantes. 0 autor parte da idéia de que a profissão vai sendo construída à medida que o professor articula o conhecimento teórico-acadêmico à cultura escolar e à reflexão sobre a prática docente. Revisando as novas perspectivas de pesquisa que analisam a questão da competência para ensinar, ele enfatiza que "esses novos paradigmas investigativos buscam a partir do pensamento e desenvolvimento profissional dos professores uma epistemologia da prática que explique como se configura o processo de aprender a ensinar, de tornar-se professor" (p. 2).

Dessa forma, numa tentativa de superar o modelo da racionalidade técnica, as pesquisas e os cursos de formação de professores precisam redirecionar as relações entre teoria e prática, centrar as análises na prática docente e procurar: 
(...) identificar quais conhecimentos são desenvolvidos pelo professor ao atuar, no âmbito da cultura escolar e das condições mais adversas do seu trabalho. Também busca especificar e estudar as necessárias articulações desses conhecimentos do professor tanto com a prática, quanto com os conhecimentos teóricos acadêmicos da formação básica. Tais articulações possibilitam o desenvolvimento da capacidade reflexiva, que favorece o compromisso com o ensino de qualidade e a competência para atuar. (p. 6)

Considerando tais idéias no desenvolvimento da pesquisa, destaca-se a possibilidade de que na prática pedagógica do professor iniciante, apareçam alguns aspectos como: a) a rejeição dos conhecimentos teóricos acadêmicos recebidos na formação por dificuldade de aplicá-los; b) a tentativa de transposição direta de uma concepção teórica; e c) a percepção dos aspectos positivos da prática docente e da cultura escolar e como elas se apresentam no contexto do trabalho, podendo ser consideradas como parâmetros para sua própria prática. Essas análises enfatizam o quanto o professor aprende a partir da prática, porém reconhecendo a necessidade de que os cursos de formação de professores, tanto iniciais como continuados, favoreçam a articulação entre a formação teórica acadêmica e os conhecimentos oriundos do universo escolar.

Em outra pesquisa desenvolvida por Caldeira (1995), houve a preocupação de investigar os saberes implícitos, construídos e apropriados pelo professor em sua prática durante a trajetória profissional e pessoal. Partindo dessa suposição (de que o docente se apropria e produz saberes na atividade escolar), a autora procurou descrever e analisar a prática docente de uma professora do ensino fundamental e a reconstrução do processo de constituição do saber. Ela ressalta a importância de considerar o estudo da prática docente como um processo informal, dinâmico, complexo e carregado de valores. Recorrendo ao estudo de Tardif et al. (1991), considera os diversos tipos de saberes (disciplinas, curriculares, profissionais e experiência) como integrantes da prática docente, sendo que a diferença estaria na relação do professor com cada um deles:

Com os saberes das disciplinas curriculares e de formação profissional mantém uma "relação de exterioridade", ou alienação, porque já os recebe determinados em seu conteúdo e forma (...) Portanto esses conhecimentos não thes pertencem, nem são definidos ou selecionados por eles. (...) Não obstante, com os saberes da experiência o professorado mantém uma "relação de interioridade". E por meio dos saberes da experiência, os docentes se apropriam dos saberes das disciplinas, dos saberes curriculares e profissionais. (p. 8)

Embora reconheça as condições singulares em que foi desenvolvida a pesquisa, a autora destaca o "valor" do saber produzido na prática cotidiana do professor. Saber esse que resulta de uma reflexão realizada, coletivamente, a partir das "condições materiais e institucionais" da escola, considerando a dimensão histórica e social em que é construída a prática docente.

O estudo desenvolvido por Borges (1995) procura analisar a construção do saber docente de professores de Educação Física. Focaliza especificamente a trajetória profissional de dois professores a partir da análise de sua formação e prática pedagógica. Pôde identificar que tanto as experiências vivenciadas no processo de escolarização, quanto às experiências esportivas, acadêmicas e profissionais contribuem na gênese dos saberes que eles mobilizam no cotidiano da prática escolar. Dessa forma, analisando a divisão existente entre quem produz e quem transmite os conhecimentos, propõe que "talvez se possa pensar que a valorização dos saberes da experiência, dos saberes docentes de um modo geral, seja uma alternativa no sentido de buscar uma maior aproximação da formação acadêmica com a realidade escolar, estreitando os vínculos na relação entre teoria e prática." (p. 14).

A partir dos estudos apresentados, percebe-se que, embora existam diferentes tipologias e formas de abordar a questão dos saberes docentes, é importante considerar na 
sua investigação não só o desenvolvimento profissional como também o desenvolvimento pessoal do professor, enfatizando que o saber é constituído a partir do contexto histórico e social vivenciado e transformado em saber da experiência.

Nessas tipologias, os conhecimentos de fontes teóricas diversas e da experiência (e de diferentes tipos de experiência profissional) são considerados, pelo menos, no nível dos modelos propostos. Embora sirvam de quadros explicativos, há necessidade de desenvolvimento de pesquisas que os comprovem e mostrem suas limitações e avanços em relação à produção na área.

Enfim, todo este panorama teve por objetivo identificar e analisar alguns estudos sobre a questão dos saberes docentes e a formação dos professores, para evidenciar como está este campo de pesquisa na realidade brasileira

\section{SABERES DOCENTES: TIPOLOGIAS E PROCESSO DE AQUISIÇÃO}

Num dos primeiros textos de Murice Tardif et al. (2001) publicado no Brasil (Os professores face ao saber: esboço de uma problemática do saber docente, Tardif, Lessard e Lahye, 1991), os autores chamam a atenção para a importância de considerar que os professores são produtores de saberes, e que estes são plurais na sua constituição e natureza.

Tardif (1991, 1999), em seus trabalhos discute os fundamentos epistemológicos da prática profissional docente. 0 eixo das discussões do autor centra-se na premissa de que a competência docente integra uma pluralidade de saberes. 0 autor identifica na práxis docente quatro modalidades: saberes da formação profissional para o magistério (ciências da educação); saberes disciplinares (específicos da área); saberes curriculares (transposição didática); e saberes de experiência (prática de ensino). saberes:

Para Tardif, o saber fazer do professor deve expressar todos esses domínios de

O (a) professor (a) padrão é alguém que deve conhecer sua matéria, sua disciplina e o seu programa, que deve possuir certos conhecimentos das ciências da educação e da pedagogia, sem deixar de desenvolver um saber prático fundado em sua experiência cotidiana com os alunos (1991, p. 221).

Com a intenção de melhor compreender a profissão docente, Murice Tardif $(2000$, 2001) e sua equipe ampliaram, através de suas pesquisas, o estudo dos saberes dos professores. De acordo com a tendência contemporânea das pesquisas qualitativas de inspiração etnográfica, eles concluem que "os saberes que servem de base para o ensino, tais como são vistos pelos professores, não se limitam a conteúdos bem circunscritos que dependeriam de um conhecimento especializado. Eles abrangem uma diversidade de objetos, de questões, de problemas que estão relacionados com seu trabalho". Nesse sentido, "os saberes profissionais são plurais, compostos e heterogêneos... bastante diversificados, provenientes de fontes variadas, provavelmente de natureza diferente" (2001, p. 213).

As aprendizagens docentes provêem de diversas fontes e momentos da vida do professor, iniciando-se antes do ingresso nos cursos de formação e continuando por toda sua prática de ensino. Tardif e Raymond (2000, p.234) destacam que os saberes docentes, além de plurais, são temporais, ou seja, adquiridos através de processos de aprendizagem e socialização, que atravessam tanto a história de vida quanto a carreira. Nesse sentido, 
muitos saberes são produzidos fora do ofício de ensinar, provêem de lugares sociais anteriores à carreira docente propriamente dita, ou fora do trabalho cotidiano.

Os autores, reconhecendo o esforço e a contribuição de muitos pesquisadores no sentido de categorizar os saberes dos professores, propõem um quadro que amplia a primeira tentativa de análise dos saberes do professor mencionada anteriormente. $\mathrm{Na}$ discussão sobre os saberes da ação docente, Tardif \& Raymond (2000) destacam a natureza dos saberes subjacentes ao ato de ensinar como o conjunto de conhecimentos, competências e habilidades que alicerçam a prática docente. Assim, procuram incorporar os saberes que têm origem na prática social e profissional àqueles que provêm de modos exteriores ao ofício de ensinar. 0 Quadro 1 que expressa esses saberes.

Quadro 1: Os saberes dos professores

\begin{tabular}{|c|l|l|}
$\begin{array}{c}\text { SABERES DOS } \\
\text { PROFESSORES }\end{array}$ & \multicolumn{1}{|c|}{$\begin{array}{c}\text { FONTES SOCIAIS } \\
\text { DE AQUISIÇÃO }\end{array}$} & $\begin{array}{c}\text { MODOS DE } \\
\text { INTEGRAÇÃO NO } \\
\text { TRABALHO DOCENTE }\end{array}$ \\
\hline Saberes pessoais & $\begin{array}{l}\text { Família, sociedade, a educação no } \\
\text { sentido lato. }\end{array}$ & $\begin{array}{l}\text { Pela história de vida e pela } \\
\text { socialização primária }\end{array}$ \\
\hline $\begin{array}{c}\text { Saberes da formação } \\
\text { escolar anterior }\end{array}$ & $\begin{array}{l}\text { Formação primária e secundária, os } \\
\text { estudos não especializados. }\end{array}$ & $\begin{array}{l}\text { Pela formação e socialização } \\
\text { pré-profissionais }\end{array}$ \\
\hline $\begin{array}{c}\text { Saberes da formação } \\
\text { profissional para o }\end{array}$ & $\begin{array}{l}\text { Instituições de formação de } \\
\text { professores, Estágios, Cursos } \\
\text { Magacistério }\end{array}$ & $\begin{array}{l}\text { Pela formação e socialização } \\
\text { profissionais nas instituições etc. } \\
\text { de formação de professores }\end{array}$ \\
\hline $\begin{array}{c}\text { Saberes dos } \\
\text { programas e livros didáticos } \\
\text { usados no trabalho }\end{array}$ & $\begin{array}{l}\text { Na utilização das “ferramentas" de } \\
\text { trabalho: Programas, livros didáticos, } \\
\text { de exercícios etc. }\end{array}$ & $\begin{array}{l}\text { Pela utilização e adaptação } \\
\text { dos instrumentos de trabalho } \\
\text { às tarefas de ensinar }\end{array}$ \\
\hline $\begin{array}{c}\text { Saberes da própria } \\
\text { experiência na docência } \\
\text { (sala de aula e na escola) }\end{array}$ & $\begin{array}{l}\text { O exercício da docência na escola, na } \\
\text { sala de aula, a experiência dos pares } \\
\text { etc. }\end{array}$ & $\begin{array}{l}\text { Pela realização do trabalho } \\
\text { de sala de aula e pela } \\
\text { socialização profissional }\end{array}$ \\
\hline
\end{tabular}

FONTE: TARDIF \& RAYMOND, 2000, p. 215.

Considerando todos esses aspectos, pode-se dizer que os saberes que servem de base para o ensino não se referem somente ao "sistema cognitivo", mas dependem também do contexto de ação e das histórias anteriores. Os autores ressaltam também que, na realidade, os fundamentos do ensino são a um só tempo, existenciais, sociais e pragmáticos:

$\rightarrow \quad$ existenciais: porque o pensamento do professor envolve a sua própria vida, suas experiências. Os professores pensam a partir de sua história de vida (intelectual, afetiva, pessoal e interpessoal);

$\rightarrow \quad$ sociais: porque os saberes profissionais são plurais, oriundos de fontes sociais diversas e adquiridos em tempos sociais diferentes. Também porque, em certos casos, são explicitamente produzidos e legitimados por grupos sociais, como, por exemplo, os professores universitários, as autoridades curriculares etc.

$\rightarrow$ pragmáticos: porque os saberes que servem de base ao ensino estão intimamente ligados tanto ao trabalho quanto à pessoa do trabalhador. Saberes ligados às funções dos professores (TARDIF e RAYMOND, 2000, p. 235).

Tardif e Raymond (2000, p. 237) entendem que esses três elementos estão relacionados a uma característica temporal dos saberes docentes:

(...) essa tripla caracterização - existenciais, sociais e pragmáticos - demonstra a dimensão temporal dos saberes do professor, saberes esses que não somente parecem ser adquiridos no e com o tempo, mas são eles mesmo temporais, pois são abertos, porosos, permeáveis, e incorporam, ao longo do processo de socialização e de carreira, experiências 
novas, conhecimentos adquiridos em pleno processo, um saber-fazer remodelado em função das mudanças de práticas, de situações de trabalho.

Pode-se dizer que conhecer e compreender os saberes dos professores é compreender, portanto, sua evolução, transformações e sedimentações sucessivas ao longo da história de vida e de uma carreira que remete a várias etapas de socialização e recomeços.

Alguns foram os méritos dessas reflexões no campo da formação de educadores no Brasil. Houve uma ampliação do delineamento dos saberes numa similaridade com os estudos de Nóvoa (1992), que vinham impactando o campo das pesquisas educacionais e analisando a constituição genealógica da docência. Além disso, mostraram que os saberes requeridos para o professor são definidos na relação histórica do papel da escola e da educação nas sociedades contemporâneas.

Esse entendimento corrobora com as idéias de Pimenta, quando ele observa que:

a profissão de professor, como as demais, emerge em dado contexto e momento históricos, como resposta a necessidades que estão postas pelas sociedades, adquirindo estatuto e legalidade. Assim, algumas profissões deixaram de existir e outras surgiram nos tempos atuais. (...) Outras não chegaram a desaparecer, mas se transformam adquirindo novas características para responderem a novas demandas sociais. Este é o caso da profissão de professor (2002, p. 18).

Nesse sentido, pode-se dizer que os saberes estão matriciados numa relação de poder macro-estrutural, que varia no tempo e no espaço, dando contornos ao papel docente e orientando estudos e políticas necessárias para sua formação, quase sempre de uma forma externa ao seu fazer cotidiano (TARDIF, 2000).

\section{4 - SABERES DO PROFESSOR UNIVERSITÁRIO}

No que se refere ao docente do ensino superior, tomando por base a realidade brasileira, os saberes também são atingidos pela estrutura de poder que permeia as distintas profissões e o prestígio que é dado às diferentes dimensões da docência neste nível de ensino. Considerando as funções tradicionais de pesquisa e ensino, espera-se que os professores construam saberes que respondam às duas demandas, para exercer sua profissão com êxito (CUNHA, 2002).

Entretanto, o que se observa é que as funções de pesquisa carregam maior valor na representação sobre o perfil docente, repercutindo sobre a sua formação e prática pedagógica. Um exemplo claro desse fenômeno "é a cultura tomar a formação de pósgraduação stricto sensu como fundante da carreira universitária, explicitando a representação de um perfil de professor e, certamente, dos saberes que são valorizados na sua formação" (CUNHA, 2002, p. 46).

Cunha (2002) apresenta algumas reflexões sobre os saberes do docente universitário e afirma que os componentes principais que permeiam sua prática na universidade são a pesquisa e a docência.

O componente da docência alimenta-se, fundamentalmente, dos saberes oriundos da história de vida dos professores, da formação profissional para o magistério (quando a graduação se deu na área da educação), e, como mostram as pesquisas, da prática enquanto professor, incorporando o trabalho como espaço e território de aprendizagem. Nessa perspectiva, a docência alimenta-se de uma ambiência de cultura, isto é, daquilo que é valor entre seus pares e no seu tempo, incluindo os aspectos que têm significado no seu campo científico. 
Essa posição vem de encontro com o que observa Pérez Gómez, quando relata que os saberes da experiência, dada a sua possibilidade de objetivação, constituem-se em componentes da cultura dos docentes, isto é, "o conjunto de crenças, valores, hábitos e normas dominantes que determinam o que este grupo social considera valioso em seu contexto profissional, assim como os modos politicamente corretos de pensar, sentir, atuar e se relacionar entre si" (PÉREZ GÓMEZ, 1999, p. 164).

Verifica-se também, que a docência está fortemente exposta aos processos regulatórios das políticas de estado. O professor não é só professor de uma determinada universidade, é também de uma área profissional, de um curso, de determinado nível de ensino. Todas essas dimensões interferem na sua docência e naquilo que ele valoriza para a realização de seu trabalho, em respeito ao processo de construção permanente.

0 componente da pesquisa também requer seus próprios saberes, principalmente, na formação acadêmica da pós-graduação e no exercício das atividades investigativas que o professor realiza, privilegiando sempre a verticalização especializada de conteúdos da sua área de conhecimento e a interlocução com a comunidade científica. Assim como acontece no ensino, a ambiência cultural também interfere na produção dos sentidos que o professor dá as suas atividades de pesquisa, vinculada, basicamente, aos estímulos pragmáticos desencadeados pelos governos e setores produtivos (CUNHA, 2002).

A Figura 1 procura explicitar, graficamente, as proposições descritas por Cunha (2002) sobre os componentes dos saberes do professor universitário.

Figura 1: Saberes do professor universitário:

\section{COMO APRENDEM OS PROFESSORES?}

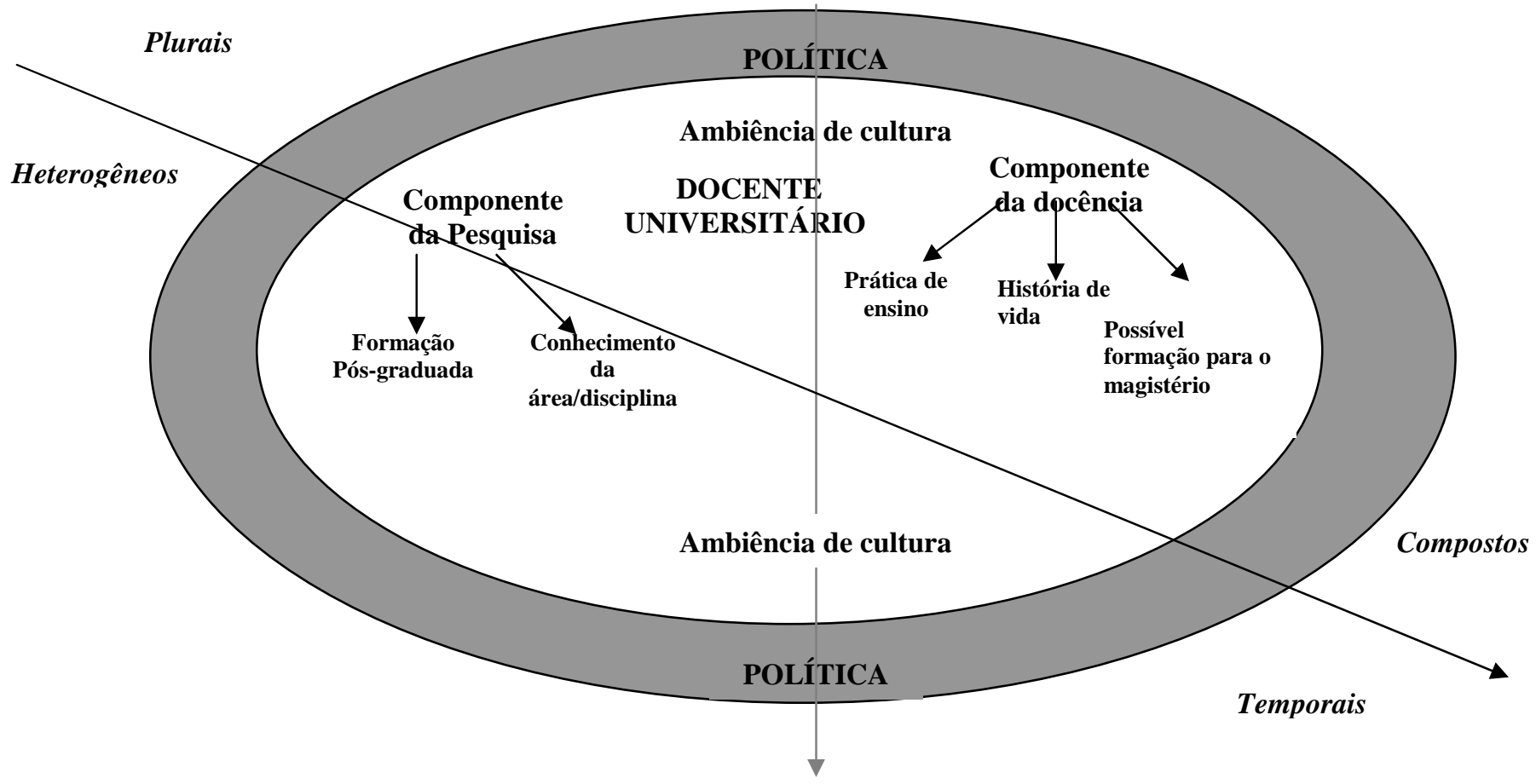

COMO E O QUE ENSINAM AOS ALUNOS?

Fonte: Elaborado pelo Autor 
Tardif \& Raymond, na reflexão sobre a organização dos saberes docentes, chamam a atenção para a importância de se fazer uma leitura abrangente dessas categorias, pois entendem que "os saberes não são imóveis e estáticos, nem foram produzidos no mesmo tempo, território e circunstâncias. Eles imbricam em novas sínteses à medida que se constroem. Estão sempre submetidos a novas interferências políticas, pessoais e profissionais" (2001, p.45).

Uma outra questão importante levantada por Cunha (2002) refere-se ao fato da investigação sobre a própria docência e os processos pedagógicos vivenciados no âmbito da universidade não ser valorizada e incentivada na maior parte das áreas acadêmicas, apesar de também constituir a dimensão da pesquisa. Essa é uma exteriorização dos valores presentes na cultura acadêmica, que indica que a docência não precisa ter o estatuto profissional requerido nas outras profissões.

\section{CONSIDERAÇÕES FINAIS}

Os saberes que compõem o trabalho do professor têm sido objeto de vários estudos por representar a possibilidade de compreender os elementos que o estruturam, visto que o trabalho docente requer do professor um fazer que atenda a uma diversidade de situações articuladas simultaneamente. Essa diversidade envolve aspectos como conhecimento sobre $\mathrm{o}$ ato de ensinar e de aprender; planejamento e preparação das atividades docentes; gestão da sala de aula, que inclui organização de espaço e tempo; escolha de metodologias, material e outros recursos adequados ao ensino; acompanhamento da aprendizagem do aluno; interação "professores-alunos" e "alunosalunos"; trabalho com as diferenças; seleção e articulação do conteúdo com as experiências de vida dos alunos entre outras questões gerais da educação referentes ao cotidiano das salas de aula e das IES. Essas são apenas algumas ações que conduzem o professor à mobilização dos saberes, que são (precisam ser) construídos durante a formação e no decorrer do exercício da profissão.

Delimitar, indicando passo a passo o que os professores precisam saber é impossível, pois, cada contexto tem suas necessidades específicas e a prática de ensino não depende de receita, não funciona segundo regras fixas, que uma vez seguidas, resultam em atividade bem sucedida. É possível, entretanto, ter uma idéia sobre os conhecimentos envolvidos no ato de ensinar e avaliar a natureza e a origem desses saberes envolvidos à prática docente.

Murice Tardif $(2000,2001)$ e sua equipe concluem que os saberes que servem de base para o ensino, tais como são vistos pelos professores, não se limitam somente a conhecimentos e conteúdos especializados; eles abrangem uma diversidade de objetos, questões e problemas relacionados ao trabalho de sala de aula e contexto. Para esses autores, os saberes profissionais são compostos de vários saberes, e são, portanto, plurais, bastante diversificados (heterogêneos), provenientes de fontes variadas, provavelmente de natureza diferente. Eles mencionam os saberes originados: “a) na história de vida pessoal; b) da formação profissional para o magistério; c) do conhecimento científico da disciplina que o professor ministra; d) dos currículos e materiais com que trata o professor; e finamente e) da sua prática pedagógica e profissional".

Os saberes que servem de base para o ensino não se referem somente ao sistema cognitivo, mas dependem também do contexto de ação e das histórias anteriores. $\mathrm{Na}$ realidade, os fundamentos do ensino são a um só tempo: "existenciais, sociais e pragmáticos" (TARDIF, 2001). 
Em relação ao professor universitário, Cunha (2002) aponta os saberes da "pesquisa" e os saberes do "ensino". Salienta, porém, que a valorização dos saberes acadêmico-científicos, em detrimento dos pedagógicos, tem sido histórica nos meios acadêmicos. As funções de pesquisa carregam maior valor na representação sobre o perfil docente, repercutindo sobre a sua formação e prática pedagógica. Desse modo, o saber gerado no ensino é desprestigiado e a investigação sobre a própria docência e os processos pedagógicos vivenciados no âmbito da universidade quase não encontram guarida nas áreas acadêmicas, apesar de também constituir a dimensão da pesquisa. Essa é uma exteriorização dos valores presentes na cultura acadêmica, em que a docência não precisa ter, o estatuto profissional requerido nas outras profissões.

0 quadro teórico-prático ora delineado sobre a questão dos saberes docentes e a formação dos professores servirá de base para um estudo empírico, pelo qual se pretende identificar quais são os saberes que fundamentam a prática de ensino dos professores de Ciências Contábeis no Brasil. Entende-se que essa temática ainda é carente de estudos empíricos que respondam às questões: como os professores constroem a prática pedagógica e realizam a transposição didática da formação que receberam? Existe um "conhecimento de base" a ser considerado na formação do professor de Ciências Contábeis? Teria esse conhecimento uma maior "relevância" sobre os demais saberes? A investigação de questões como essas, entre outras referentes ao saber docente, certamente, contribuirá bastante para o desenvolvimento desse campo de pesquisa na realidade brasileira, assim como pode orientar as políticas voltadas para a formação e profissionalização do professor, especialmente de Ciências Contábeis.

\section{REFERÊNCIAS}

ANDRÉ, Marly E. O papel da pesquisa na articulação entre saber e prática docente. CLAVES, S. M. e TIBALLI, E. F. (orgs). Anais do VII ENDIPE, Vol II, Goiânia, p. 291-296, 1994.

APPLE, Michael, TEITELBAUN, Kenneth. Está o professor perdendo o controle de suas qualificações e do currículo? Teoria e Educação, n 4, 62-73, 1991.

ARAÚJO, J.C.S. Docência e ética: da dimensão interativa entre sujeitos ao envolvimento sócio institucional. In: ROMANOWISKI, J.P.; MARTINS, R.D.O.; JUNQUEIRA, S.R. (Orgs.). Conhecimento local e conhecimento universal: práticas sociais, aulas, saberes e políticas. Curitiba: Champagnat, 2004.

BORGES, C. M.F. Formação e prática pedagógica do professor de educação física: $A$ construção do saber docente. In: Anais da $19^{a}$ Anped, 1996.

BORGES, C.M.F. Formação e prática pedagógica do professor de educação física: A construção do saber docente. In: Anais da $19^{\mathrm{a}}$ Anped, 1996 (disq.).

BOURDIEU, P. Campo do poder, campo intelectual e habitus de classe. In: Economia das trocas simbólicas. Rio de Janeiro: Perspectiva, 1992, p. 201 - 2.

CALDEIRA, M.S. A apropriação e a construção do saber docente e a prática cotidiana. Cadernos de Pesquisa n ${ }^{\circ}$ 95, São Paulo, nov. 1995, p. 5-12.

CERVO, A. \& BERVIAN. P. Metodologia científica. $5^{\circ}$ ed. São Paulo: Prentice Hall, 2002.

CHEVALLARD, Y. La transposition didactique: du savoir savant au savoir enseigné. Grenoble: La Pensée Sauvage, 1985.

CUNHA, M. I. Impactos das políticas de avaliação externa na configuração do docência. In: GONÇALVES ROSA, D. e SOUZA, V.C. Políticas organizativas e curriculares, educação inclusiva e formação de professores. Rio de Janeiro: DP\&A, 2002.

CUNHA, Maria Isabel et alii. Projeto de Pesquisa Formatos avaliativos e concepção de docência. Relatório parcial. São Leopoldo, 2001. 
CURY, C. R. J. LDB Lei de Diretrizes e Bases da Educação Lei 9.394/96. São Paulo: DP\&A, 2002.

DIAS SOBRINHO, José. Dilemas da Educação Superior no Mundo Globalizado: Sociedade do Conhecimento ou Economia do Conhecimento? São Paulo: Casa do Psicólogo, 2005.

ELBAZ, F. Teacher thinking: a study of Practical Knowledge. Londres: Croom Helm, 1983.

ENGUITA, Mariano. A ambigüidade da docência: entre o profissionalismo $e$ a proletarização, Teoria e Educação. Porto Alegre, n.04, p.41-61, 1991.

FIORENTINI, D. \& SOUZA e MELO, G. F. Saberes docentes: Um desafio para acadêmicos e práticos. In: GERALDI, C. (org). Cartografias do trabalho docente: Professor(a)pesquisador(a). Campinas: Mercado das Letras, ALB, 1998.

FORGRAD, Plano Nacional de Graduação: um projeto em construção. In: ORGRAD. Resgatando espaços e construindo idéias. $3^{\mathrm{a}}$ ed. ampl. Uberlândia: Edufu, 2004.

GARCÍA, Marcelo. Pesquisa sobre a formação de professores - o conhecimento sobre aprender a ensinar. In: Revista Brasileira de Educação, São Paulo, n 9, Jun. 1998.

A formação de professores: novas perspectivas baseadas na investigação sobre o pensamento do professor. In: NÓVOA, A. (Org.) Os professores e a sua formação. Lisboa: Dom Quixote, 1992.

GAUTHIER, C. Por uma teoria da pedagogia. Pesquisas contemporâneas sobre o saber docente. Ijuí (RS): Unijuí, 1998.

GIMENO SACRISTAN, José, PEREZ GOMEZ. Compreender e transformar o ensino.Porto Alegre, Artmed, 1998.

GUARNIERI, M.R. O início na carreira docente: Pistas para o estudo do trabalho do professor. In: Anais da Anped, 1997 (disq.).

HIPÓLYTO, Alvaro. Processos de trabalho na escola: algumas categorias para análise. Teoria e Educação, $\mathrm{n}^{\circ}$ 4, 03-21, 1991.

KOURGANOFF, W. A face oculta da Universidade. São Paulo: Editora UNESP, 1990.

KRAMER, Sonia e ANDRÉ, Marli. Alfabetização: um estudo sobre professores das camadas populares. Revista Brasileira de Estudos Pedagógicos, $\mathrm{n}^{\circ}$ 151. Brasília, set/dez. 1984, pp. 507-738.

NÓVOA, A. (Coord.). Os professores e sua formação. Lisboa, Dom Quixote, 1992.

. Profissão professor. Porto: Porto Editora, 1995.

PÉREZ GOMÉZ, A. I. O pensamento prático do professor - A formação do professor como profissional reflexivo. In: NÓVOA, A. (Org.) Os professores e a sua formação. Lisboa: Dom Quixote, 1992.

PEREZ GOMEZ, Angel. El practicum de enseñanza y la socialización profesional de los futuros docentes. In: PEREZ GOMEZ, A., BERQUIN RUIZ, J. ANGULO RASCO, F. (orgs). Desarrollo profesional del docente. Política, investigación y práctica. Madrid, Akal Editores, 1999. 599-635.

PERRENOUD, P. Construir as competências desde a escola. Porto Alegre: Artmed, 1999.

.Práticas pedagógicas e profissão docente: perspectivas sociológicas. 2. ed. Dom Quixote: Lisboa, 1996.

PIMENTA, S. G. \& ANASTASIOU, L. G. C. Docência no ensino superior. São Paulo: Cortez, 2002 (Coleção Docência em formação).

PIMENTA, S.G. Formação de professores: Identidade e saberes da docência. In: PIMENTA, S.G. (Org.) Saberes pedagógicos e atividade docente. São Paulo: Cortez, 1999.

PIMENTEL, Maria da Glória. O professor em construção. Campinas, Papirus, 1993.

SACRISTÁN, J. G. Consciência e ação sobre a prática como libertação profissional dos professores. In: NÓVOA, A. (Org.). Profissão professor. Porto: Porto Editora, 1995.

SCHÖN, A. D. Educando o profissional reflexivo: um novo design para o ensino e a aprendizagem. Porto Alegre: ArtMed, 2000.

Educating the reflective practitioner: toward a new designer for teaching and learning in the professions. San Francisco: Jossey - Bass Publ., 1987. 
SCHÖN, D. A. The reflective practitioner: how professionals think in action. Nova York: Jossey Bass. 1983.

SEVERINO, A J. Metodologia do trabalho científico. 21. ed. São Paulo: Cortez, 2000.

SHULMAN, L. Knowledge and teaching: Foundations of the new reform. In: Havard Educational review. Vol.57 № 1 February 1987a. (1-21).

Those who understand: knowledge growth in teaching. In Educational Researcher, 15(2), 1986, (4-14).

STENHOUSE, L. An introduction to curriculum research and development. Londres, Heinemann, 1975.

TARDIF, M. Saberes profissionais dos professores e conhecimentos universitários. Quebec: CRIFPE 1999.

. Saberes docentes e formação profissional. 2. ed .Petrópolis, RJ: Vozes, 2002.

TARDIF, M.; LESSARD e LAHAYE. Os professores face ao saber. Esboço de uma problemática do saber docente. In: Teoria e Educação. N. 4. Porto Alegre, Pannonica: Editora, 1991.

TARDIF, M.; LESSARD, C.; GAUTHIER, C. (orgs.), Formation des maîtres et contextes sociaux. Paris: PUF, 1998.

TARDIF, M.; RAYMOND, D. Saberes, tempo e aprendizagem do trabalho no magistério. Educação e Sociedade, ano XXI, n. 73, dez. 2000.

VEIGA, Ilma. A prática pedagógica do professor de didática. Campinas, Papirus, 1989.

ZABALZA, M.A. O ensino universitário: seu cenário e seus protagonistas. Porto Alegre: Artmed, 2004.

ZEICHNER, Kenneth. A formação reflexiva de professores: idéias e práticas. Lisboa, Educa, 1993.

\title{
ENDEREÇO DOS AUTORES
}

\author{
Fundação Escola de Comércio Álvares Penteado \\ Av. Liberdade, 532 - Liberdade \\ Sao Paulo, SP - Brasil \\ 01502-001
}

